Research Article

\title{
Development of Future Rule Curves for Multipurpose Reservoir Operation Using Conditional Genetic and Tabu Search Algorithms
}

\author{
Anongrit Kangrang $\mathbb{B D}^{1}{ }^{1}$ Haris Prasanchum, ${ }^{2}$ and Rattana Hormwichian ${ }^{1}$ \\ ${ }^{1}$ Faculty of Engineering, Mahasarakham University, Kantharawichai, Mahasarakham 44150, Thailand \\ ${ }^{2}$ Faculty of Engineering, Rajamangala University of Technology Isan, Khon Kaen Campus, Muang, Khon Kaen 40000, Thailand
}

Correspondence should be addressed to Anongrit Kangrang; anongrit.k@msu.ac.th

Received 28 July 2017; Revised 21 October 2017; Accepted 6 November 2017; Published 11 February 2018

Academic Editor: Ravipudi V. Rao

Copyright ( 92018 Anongrit Kangrang et al. This is an open access article distributed under the Creative Commons Attribution License, which permits unrestricted use, distribution, and reproduction in any medium, provided the original work is properly cited.

Optimal rule curves are necessary guidelines in the reservoir operation that have been used to assess performance of any reservoir to satisfy water supply, irrigation, industrial, hydropower, and environmental conservation requirements. This study applied the conditional genetic algorithm (CGA) and the conditional tabu search algorithm (CTSA) technique to connect with the reservoir simulation model in order to search optimal reservoir rule curves. The Ubolrat Reservoir located in the northeast region of Thailand was an illustrative application including historic monthly inflow, future inflow generated by the SWAT hydrological model using 50-year future climate data from the PRECIS regional climate model in case of B2 emission scenario by IPCC SRES, water demand, hydrologic data, and physical reservoir data. The future and synthetic inflow data of reservoirs were used to simulate reservoir system for evaluating water situation. The situations of water shortage and excess water were shown in terms of frequency magnitude and duration. The results have shown that the optimal rule curves from CGA and CTSA connected with the simulation model can mitigate drought and flood situations than the existing rule curves. The optimal future rule curves were more suitable for future situations than the other rule curves.

\section{Introduction}

Nowadays, water resource issues have become more complex, which is related to global climate change and land-use change due to population and economic growth, which are increasing rapidly. For water resource management, both demand management site and supply management site are often required to solve the problems. Improving the reservoir operation for increased efficiency is another way of supply management site, which does not require the physical development of reservoir. Normally, reservoir operation uses upper and lower rule curves to consider the release of water from the reservoir responding to downstream demands in long-term operation. The purpose of the rule curves for reservoir operation was divided into two main areas: (i) variation of hydrological conditions [1], such as precipitation and inflow that flows into the reservoir were affected by climate change, and (ii) water allocation for social, economic, and engineering purposes in downstream areas has changed due to the population growth and landuse demand. The reservoir management agency (such as the Royal Irrigation Department of Thailand) needs to plan in advance the appropriate volume of water in the reservoir (at each time interval) for storage and release of water for various purposes [2], including the implementation of the plan as long as the relevant factors in the future have not changed from the original. However, if future conditions are different from those anticipated in the planning phase, performance may differ from planned to minimize water shortage or overflow. The rule curve assumptions are based on maintaining the water level (or volume of water) in the reservoir to appropriate the changing hydrological situation [3] and downstream water allocation (according to the time period, which is generally one year). The main purpose is to avoid the risk of water shortages and floods in the reservoir and downstream areas. During the dry season, reservoirs 
need to maintain water volume to reduce the risk of water levels lower than minimum storage. During the rainy season, the reservoir must release water to reduce the storage volume, which can support the precipitation and inflow that flows into the reservoir. This also includes prevention of overflow situation in the reservoir [4]. The reservoir rule curves have been improved to provide the optimal solution for long-term operation. Typically, reservoir operating system has been large and complex, especially in watershed areas having both drought and flood situations [5].

To search optimal rule curves of the reservoir is a nonlinear optimization problem. There are many optimization techniques that are applied to connect with the reservoir simulation model for searching optimal rule curves such as dynamic programming (DP), genetic algorithm (GA), and simulated annealing algorithm (SA) [6-10]. Those obtained rule curves are effectively applied for each area. However, these new optimization techniques have not been applied to find the optimal rule curves like the tabu search technique.

In the last decades, there are many alternative algorithms to solve complex computational problems. Tabu search is a heuristic procedure designed for solving optimization problems. It has been successfully applied to many engineering fields such as industrial engineering, electrical engineering, civil engineering, and water resources engineering $[11,12]$. Tabu search is a very aggressive heuristic for overcoming local optima and searching for global optimality by exploring other regions of the solution space. Its efficiency depends on the fine-tuning of some parameters [13-15].

This study proposed a conditional tabu search algorithm (CTSA) to connect with the simulation model for searching the optimal reservoir rule curves. A minimum average water shortage was used as the objective function for the searching procedure. The proposed model has been applied to determine the optimal rule curves of the Ubolrat Reservoir in the northeast region of Thailand with the historic monthly inflow, future inflow under scenario B2, water demand, hydrologic data, and physical reservoir data. Comparison of the conditional genetic algorithm (CGA) and the CTSA was shown to demonstrate the effectiveness of the proposed CTSA model.

\section{Methodology}

2.1. Future Inflow into the Ubolrat Reservoir. The development of the optimal future rule curves will use data from the future inflow flowing into the Ubolrat Reservoir considering the effects of climate change using the PRECIS model. Thus, the future inflow will be produced using the SWAT hydrological model. For the future climate data in the study area, PRECIS is a regional climate model, based on the development of ECHAM4 model, displaying the data as "grid" with high solution of $22 \times 22 \mathrm{~km}^{2}$ [16]. The data recorded during 1997-2014 were used as a baseline to predict those for 2015 to 2064 . These data present the precipitation and maximum and minimum temperatures.

Because of the Ubolrat Reservoir and the study area located in northeastern Thailand, most of the economic characteristics are generated by the sale of major agricultural products, such as rice and sugarcane, which require water for
TABLE 1: Spatial data and observed inflow data for SWAT performance evaluation.

\begin{tabular}{lccc}
\hline Data types & Period & Scale & Source \\
\hline Spatial data (model input) & & \\
DEM & 2011 & $30 \times 30 \mathrm{~m}$ & \\
River map & 2011 & $1: 50,000$ & Land Development \\
Soil types & 2011 & $1: 50,000$ & $\begin{array}{c}\text { Department, Thailand } \\
\text { Land use map }\end{array}$ \\
Climate & 2014 & $30 \times 30 \mathrm{~m}$ & \\
Observed inflow (model performance assessment) & Electricity Generating \\
Ubolrat Dam & 1997-2014 & Daily & Authority of Thailand \\
\hline
\end{tabular}

cultivation during the rainy season as the primary source. The expansion of most urban areas in the region is slow. Therefore, this study has chosen the appropriate greenhouse gas emission projection model based on the model of socioeconomic development, population growth, and technology of the study area according to the IPCC SRES, with emphasis on regional development for the emission scenario B2-prediction of lower population growth than A2, moderate-level economic development, and oriented toward environmental protection [17].

SWAT (Soil and Water Assessment Tool) [18] is a semidistributed hydrological model developed for the measurement of the inflow, sediment, and water quality under the climate and land-use changes [19]. SWAT can be used to continually measure the daily inflow and define a longer period of time in the future. It can also connect and import the spatial data from the Geographic Information System (GIS) in order to evaluate the inflow. The spatial data and SWAT performance evaluation are presented in Table 1.

The accuracy of the SWAT results can be evaluated by comparing the simulated data with that recorded data from the observation station (i.e., Ubolrat Reservoir). Three variables including $R^{2}$ (coefficient of determination), $\mathrm{RE}$ (relative error), and $E_{\mathrm{ns}}$ (Nash-Sutcliffe simulation efficiency) were considered as the key indicator of the accuracy. In general, SWAT needs to modify the value of hydrological parameters for the model calibration and validation [20]. In this study, 8 parameter values were used including Alpha_BF, Gwqmn, Gw_Revap, Sol_Awc, Epco, Esco, Ch_N2, and Gw_delay. Then, the SWAT with adjusted sensitivity parameters was optimized (calculated results are close to the observed data); it was considered to be suitable for calculating the future inflow. Later, the daily future climate data from PRECIS that had been downscaled were classified into 50 years in future periods; the processes of model setup are shown in Figure 1.

2.2. Reservoir Operation Model. Reservoir system comprises available water that flows from upstream into the reservoir and multipurpose downstream demand. The reservoir operation is performed using water usage criteria release, operating policies, and reservoir rule curves with monthly 


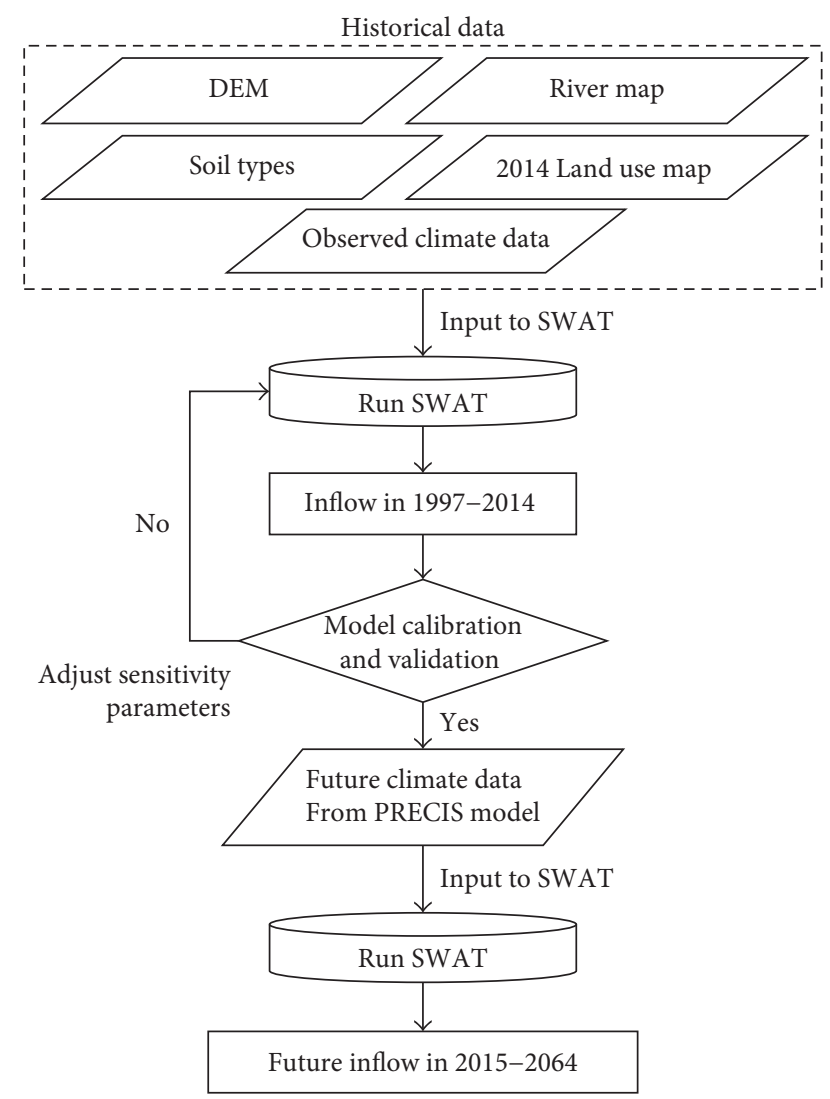

FIgURE 1: Model setup processes for future inflow.

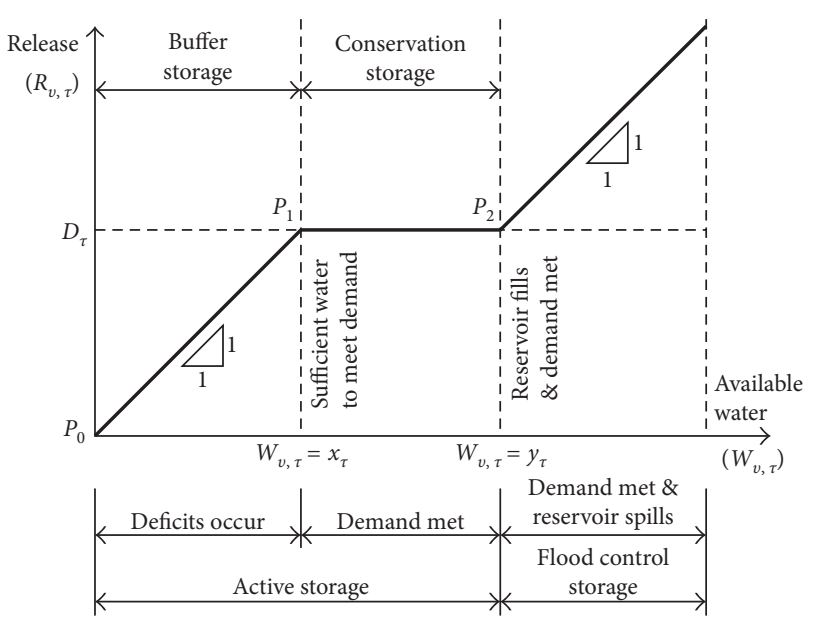

FIgURE 2: Standard operating rule.

data for long-term period. A reservoir operation model was constructed on the concept of water balance, and it can be used to simulate reservoir operation effectively. The reservoir operating policies are based on the monthly rule curves of individual reservoirs and the principles of water balance equation under the reservoir simulation model. The existing standard operating policies used for the reservoir rule curves operation are presented in Figure 2. The $y$-axis is defining the total water released, and the $x$-axis is defining the available water. The available water is represented as the total of inflow and starting point of storage in the reservoir during the period. In case of where demand is constant, water is not conserved for future demand, and if the available water is less than water demand, all of water in the reservoir is released and the reservoir is emptied [21]. At the point $\mathrm{P}_{1}$, the available water is equal to the water demand, and at the point $\mathrm{P}_{2}$, the available water is the total of reservoir capacity and water demand. If the available storage is between $P_{1}$ and $P_{2}$, water release is equal to water demand. The line between $\mathrm{P}_{0}$ and $\mathrm{P}_{1}$ makes the ratio of $1: 1\left(45^{\circ}\right)$ [22]. On the other hand, if the available water exceeds the sum of active storage and water demand, the reservoir will release the excess spilled [23]. In addition, the standard operating policies can also be calculated from

$$
R_{v, \tau}= \begin{cases}D_{\tau}+W_{v, \tau}-y_{\tau} & \text { for } W_{v, \tau} \geq y_{\tau}+D_{\tau} \\ D_{\tau} & \text { for } x_{\tau} \leq W_{v, \tau}<y_{\tau}+D_{\tau} \\ D_{\tau}+W_{v, \tau}-x_{\tau} & \text { for } x_{\tau}-D_{\tau} \leq W_{v, \tau}<x_{\tau} \\ 0 & \text { otherwise, }\end{cases}
$$

where $R_{v, \tau}$ is the released water from the reservoir during year $v$ and period $\tau$ ( $\tau=1$ to 12 , representing January to December), $D_{\tau}$ is the water demand of month $\tau ; x_{\tau}$ is the lower rule curve of month $\tau$; $y_{\tau}$ is the upper rule curve of month $\tau$, and $W_{\nu, \tau}$ is the available water calculating by a simple water balance, as described in

$$
W_{\nu, \tau}=S_{v, \tau}+Q_{v, \tau}-R_{\nu, \tau}-E_{\tau}-D S
$$

where $S_{\gamma, \tau}$ is the stored water at the end of month $\tau ; Q_{\nu, \tau}$ is the monthly inflow to reservoir, $E_{\tau}$ is the average value of evaporation loss, and $D S$ is the minimum reservoir storage capacity (the capacity of dead storage).

In (2) and Figure 2, if available water is in the range of the upper and lower rule levels, then demands are satisfied in full. If available water is over the top of the upper rule level, then the water is spilled from the reservoir in downstream river in order to maintain water level at the upper rule level. If available water is under the bottom of the lower rules level, a reduction of water release is performed. The operating policy usually reserves the available water $\left(W_{\nu, \tau}\right)$ for reducing the risk of water shortage in the future, when $0 \leq W_{\nu, \tau}<x_{\tau}-D_{\tau}$ under long-term operation.

The released water from the reservoir was used to calculate the water shortage and excess water release situations, which can be expressed as the frequency of failures in a year and the number of excess water release, as well as the average annual shortage (as the objective function for searching the optimal rule curves in this study). The results were recorded and used to develop the CTSA model.

2.3. Application of CGA with the Reservoir Simulation Model for Searching Rule Curves. The connection of the CGA to the reservoir simulation model was as follows. The CGA requires an encoding format to change the decision variables into the form of chromosomes. The CGA, which consists of selection, crossover, and mutation, is executed. After this stage, the genetic operations will create new chromosomes. For this study, each decision variable represents the average 


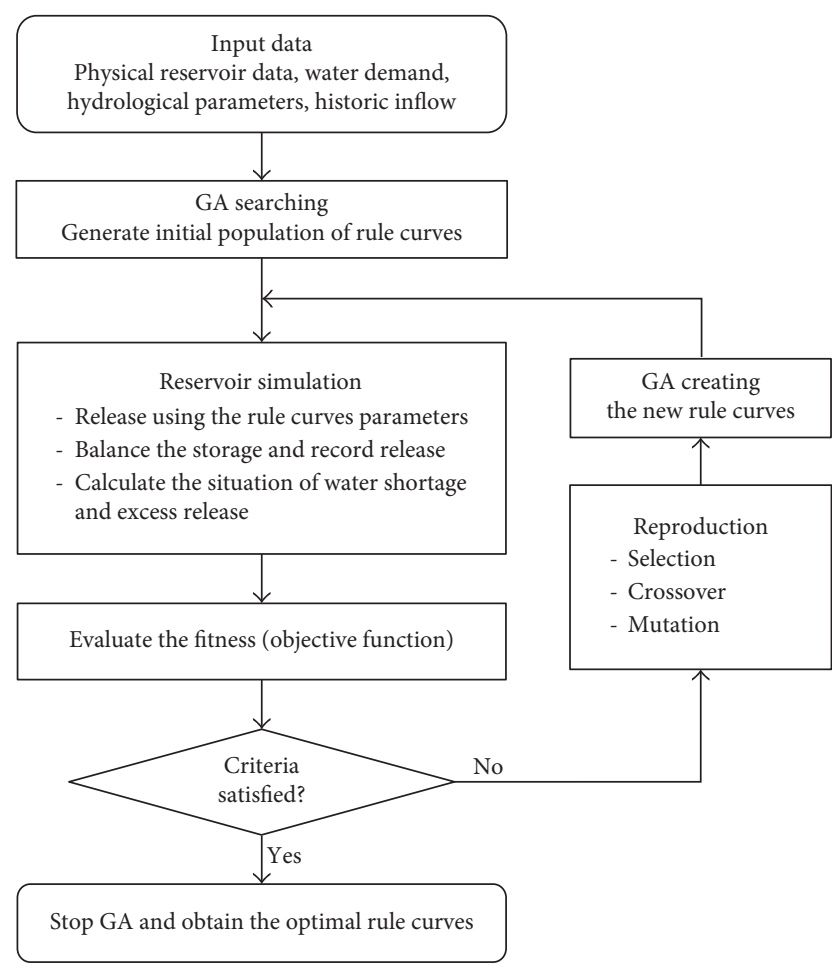

FIGURE 3: Applying CGA and reservoir simulation for searching rule curves.

monthly water storage of the rule curves in the reservoirs, which are defined as the upper bound and the lower bound. After the first set of chromosomes in the initial population have been calculated ( 24 decision variables, which consist of 12 values from the upper bound and 12 values from lower bound situations), the released water will be recalculated by the reservoir simulation model using these rule curves. Next, the released water is used to determine the objective function with the aim of assessing the fitness of the GA. After that, the reproduction process will create new rule curve values in the next generation. This procedure is repeated until the 24 values of rule curves are appropriate. The CGA and reservoir simulation model for searching the rule curves are described in Figure 3.

In this study, the objective function for searching the optimal reservoir rule curves is the minimum of the average water shortage $\left(\min _{(\mathrm{avr})}\right)$ in million cubic meters $(\mathrm{MCM})$ per year, as shown in

$$
\min _{(\mathrm{avr})}=\frac{1}{n} \sum_{v=1}^{n} S h_{v},
$$

where $n$ is the total number of considered years and $S h_{v}$ is the water deficit during year $v$ (a year that does not meet $100 \%$ of the target demand).

2.4. Applying Conditional Tabu Search Algorithm for Searching Rule Curves. The developed CTSA for searching rule curves is described as follows. The CTSA begins with an initial population $\left\{X_{1}, X_{2}, \ldots, X_{n}\right\}$ created randomly within the feasible space. With the 24 decision variables (rule curve

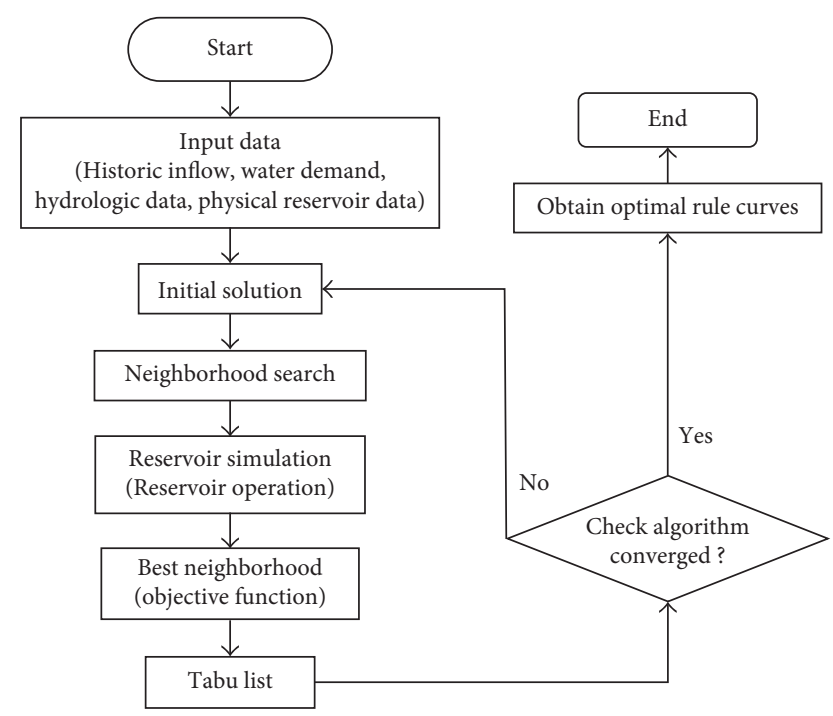

FIgURE 4: Applying tabu and reservoir simulation for searching rule curves.

variables for both upper and lower), the feasible solution of the iteration $i$ th is represented as $X_{i}=\left[x_{i 1}, x_{i 2}, \ldots, x_{i 24}\right]^{T}$. Then, a set of rule curves is used in reservoir simulation, and the released water is calculated by the simulation model using these rule curves. Next, the released water is used to calculate the fitness function to evaluate the feasible solution. The fitness function is the minimum of the average water shortage $(Z)$ subject to constraints on the simulation model as described in (3).

Then, the process is continued until the termination criterion is satisfied as described in Figure 4. This termination criterion is optimum; it can be expressed by a slight change in the fitness values (less than 0.10 MCM).

2.5. Illustrative Application. The Ubolrat Basin is a branch of the Chi Basin located in northeastern Thailand (Figure 5). It has an area of about $3,282 \mathrm{~km}^{2}$. The average annual rainfall is $1,411 \mathrm{~mm}$, and the mean annual temperature is $27^{\circ} \mathrm{C}$. The Phong River lies in the middle of the basin. The Ubolrat Dam was developed by building an earth core rock fill dam across the Phong River with a height of $33 \mathrm{~m}$ and crest length of $7,800 \mathrm{~m}$. The normal storage capacity and average annual inflow are 2,263 MCM and 2,478.591 MCM, respectively. The objectives of the Ubolrat Dam are irrigation, flood control, and industrial and domestic water supply. Schematic diagram of Ubolrat basin is described in Figure 6.

The study used CTSA in connection with a reservoir operation model to find optimal rule curves through the MATLAB toolbox. The optimal rule curve can then be applied to an actual scenario depending on whether the rule curve can be used to cover every case or event that might occur. Thus, the HEC-4 model was used to create the synthetic inflow data into the monthly inflows as a synthetic data set of 500 events. This method was based on the actual historic monthly inflow of the Ubolrat Reservoir between 


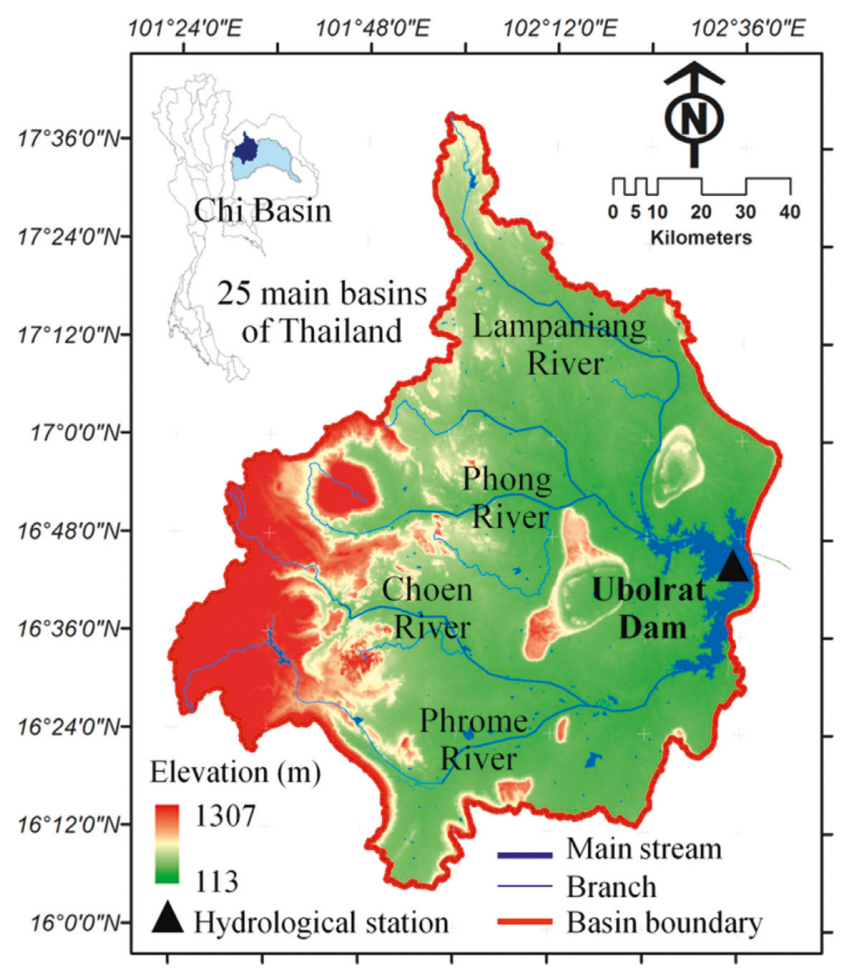

FIgURE 5: Location of the Ubolrat Dam.

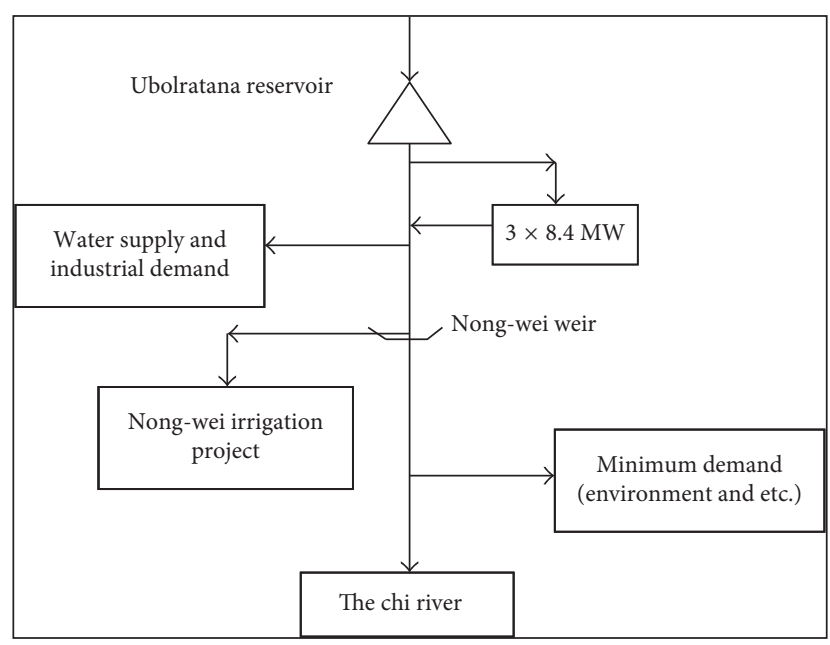

Figure 6: Schematic diagram of the Ubolrat basin.

years 1963 and 2014 (50 years) imported to the HEC-4 model to generate the synthetic inflow event. (1 event is a representative period of 50 years.) Therefore, the monthly inflow data are 300,000 values (50 years $\times 12$ months $\times 500$ events). Then, input synthetic inflow data were used to assess the efficiency of the new rule curves and compare them with the existing rule curves and also between the CTSA and CGA model under the same conditions. Further, the new obtained rule curves from CTSA and CGA model were used to evaluate with the future situation of B2 scenario [24]. The future inflows to reservoir were created by SWAT model that considered climate changes [25-28].
TABLE 2: SWAT sensitivity parameters.

\begin{tabular}{lccc}
\hline No. & Parameter & Range & Adjusted Values \\
\hline 1 & ALPHA_BF & $0-1$ & 0.025 \\
2 & GWQMN & $0-500$ & 0 \\
3 & GW_REVAP & $0-500$ & 1.25 \\
4 & SOL_AWC & $0-1$ & 0.28 \\
5 & EPCO & $0-1$ & 0 \\
6 & ESCO & $0-1$ & 0.52 \\
7 & CH_N2 & - & 0.035 \\
8 & GW_DELAY & $0-500$ & 31 \\
\hline
\end{tabular}

TABLE 3: SWAT performance evaluation index.

\begin{tabular}{lccccc}
\hline \multirow{2}{*}{ Range } & \multicolumn{2}{c}{$\begin{array}{c}\text { Average annual inflow } \\
(\mathrm{MCM})\end{array}$} & \multicolumn{3}{c}{ Assessment index } \\
& Observed & Simulation & $R^{2}$ & $\mathrm{RE}$ & $E_{\mathrm{ns}}$ \\
\hline Calibration & $2,858.8$ & $2,413.1$ & 0.89 & 15.6 & 0.80 \\
Validation & $1,421.4$ & $1,380.1$ & 0.91 & 2.3 & 0.89 \\
\hline
\end{tabular}

\section{Results and Discussion}

3.1. Future Inflow into the Ubolrat Reservoir. An evaluation on SWAT accuracy used the data found during 1997-2014 (18 years; 1997-2008 for calibration and 2009-2014 for validation) for Ubolrat Reservoir station. Practically, 8 parameter values were selected and used to analyze the flexibility score as the modified parameter values of the flexibility by adjusting the inflow volume to closely match with the data from the observed station as presented in Table 2.

The inflow calculated by SWAT and compared with the data from the two observed station shows the inflow during the period of model calibration and validation; meanwhile, $R^{2}, \mathrm{RE}$, and $E_{n s}$ were satisfactory and accurate as the deviation can be accepted as presented in Table 3; the goodness of fit of the data was depicted in Figure 7.

The inflow at the Ubolrat Reservoir station simulated by SWAT was divided into 2 phases: (1) baseline inflow which is the climate and spatial data recorded during 1997-2014 and (2) future inflow using the climate data from PRECIS model resulted during 2015-2064. The inflow analysis indicates that an average volume of the baseline inflow was 2,736 MCM and an average volume of the future inflow was 4,580.5 MCM. When comparing those two volumes, it was noted that the future inflow seems to be increased $(1,844.5 \mathrm{MCM}$ or $40.3 \%$ in 50 future years). Figure 8 illustrates the annual inflow simulated by SWAT during 20152064, and Figure 9 depicts the comparative result between the average baseline inflow and the average 10-year future inflow with increased trend in the future period, most of which have shown more than 4,000 MCM, except the third period. This result shows that the future inflow flows into the Ubolrat Reservoir with increased volume.

3.2. Optimal Historic Rule Curves. The historic data of inflow, evaporation, water requirement, and monthly rainfall 


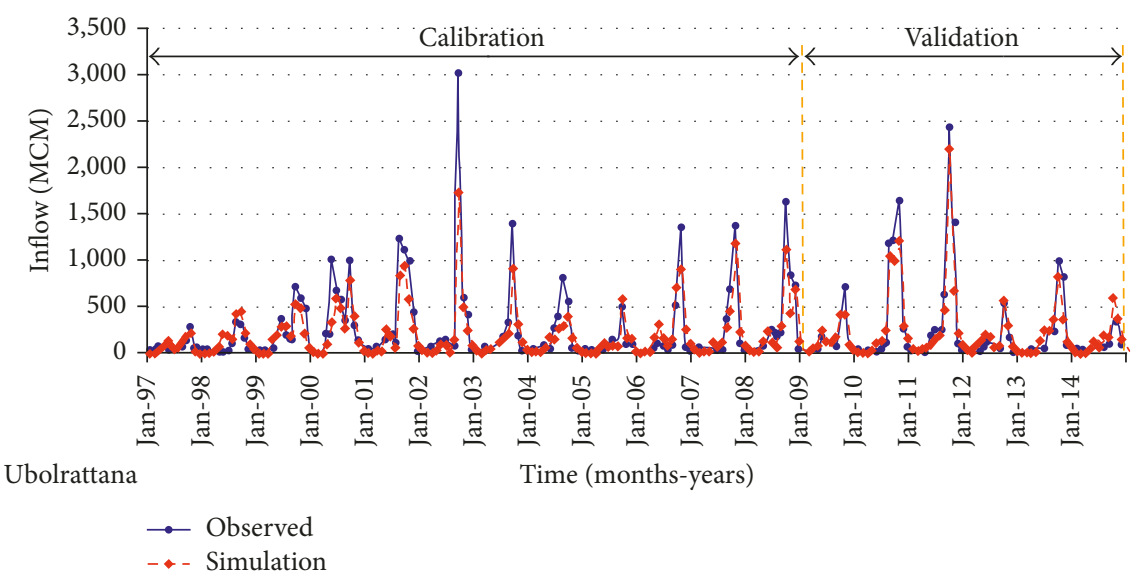

FIgURE 7: The comparison between the runoff from the observed stations and the SWAT result.

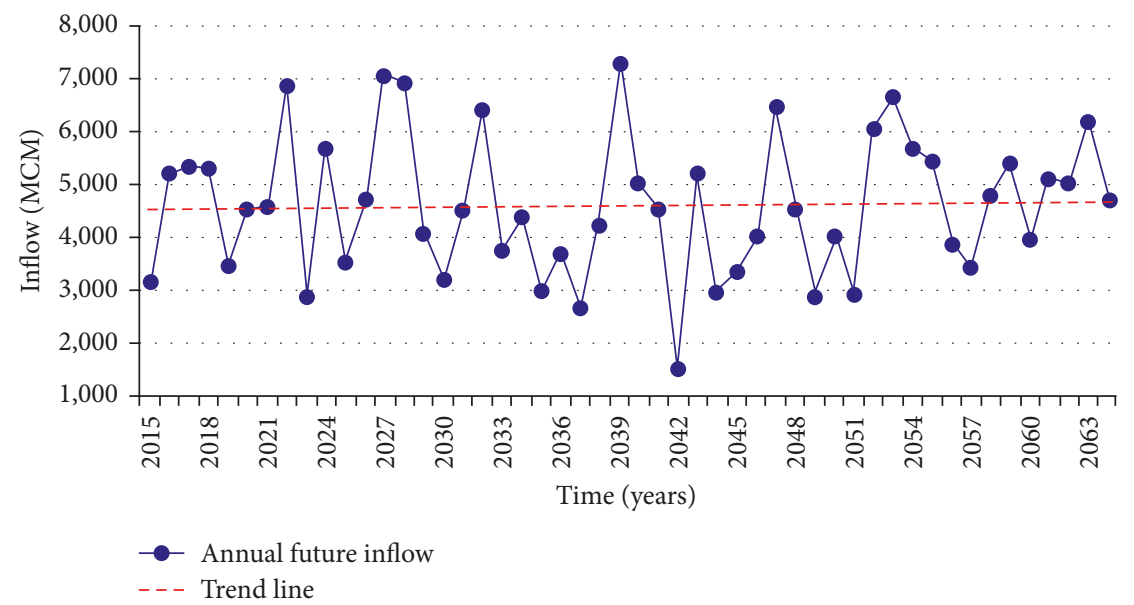

FIgURE 8: Annual future inflow flowing into Ubolrat Reservoir during 2015-2064.

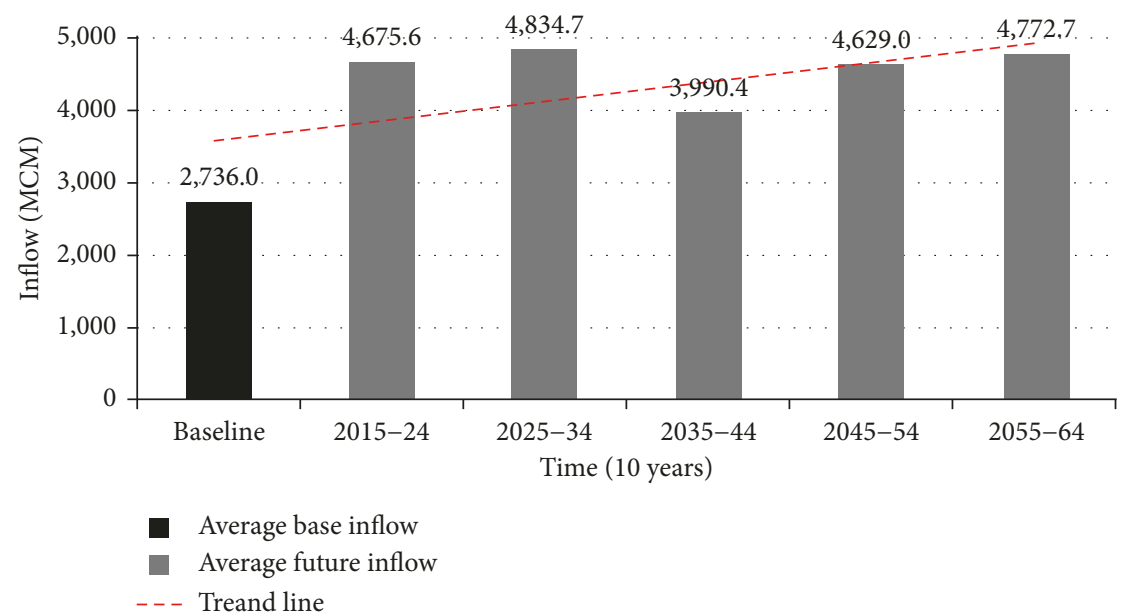

Figure 9: Average 10-year future inflow flowing into Ubolrat Reservoir compared with the baseline.

were imported for processing in the CGA connected to the simulation model and CTSA model, and the optimal rule curves were obtained. These obtained rule curves are plotted in order to compare them with the existing rule curves as shown in Figure 10. They indicated the optimal upper and lower rule curves for the CTSA (RC4) compared with the existing rule curves (RC1) and the rule curves obtained using CGA (RC2). The results show that the patterns from the 


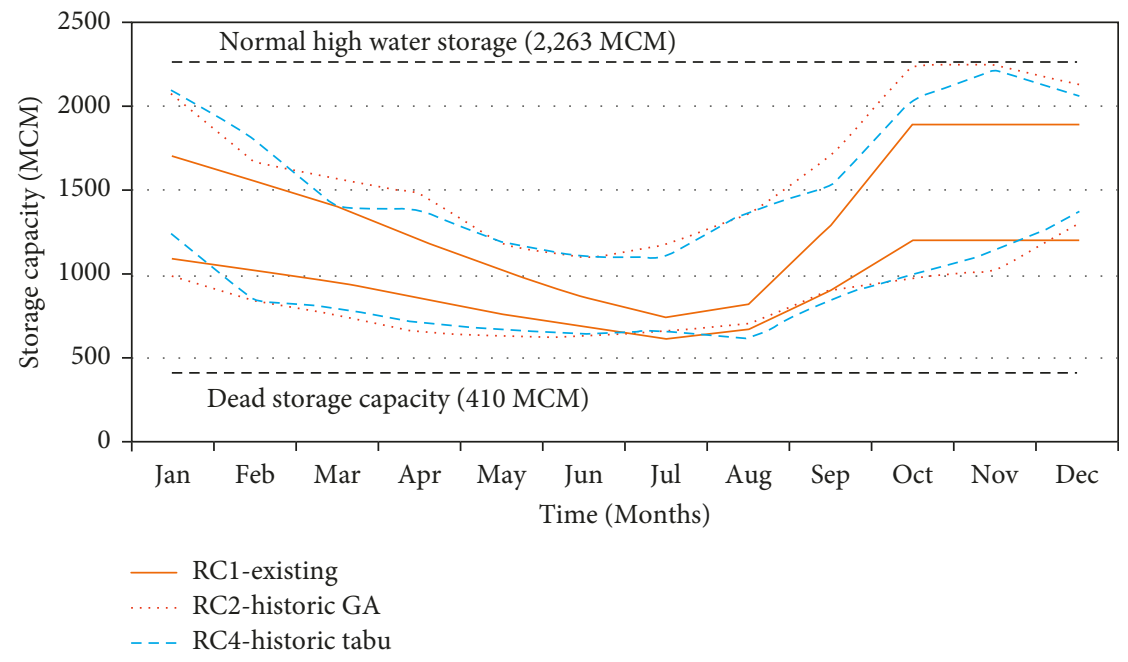

Figure 10: Optimal historic rule curves of the Ubolrat Reservoir.

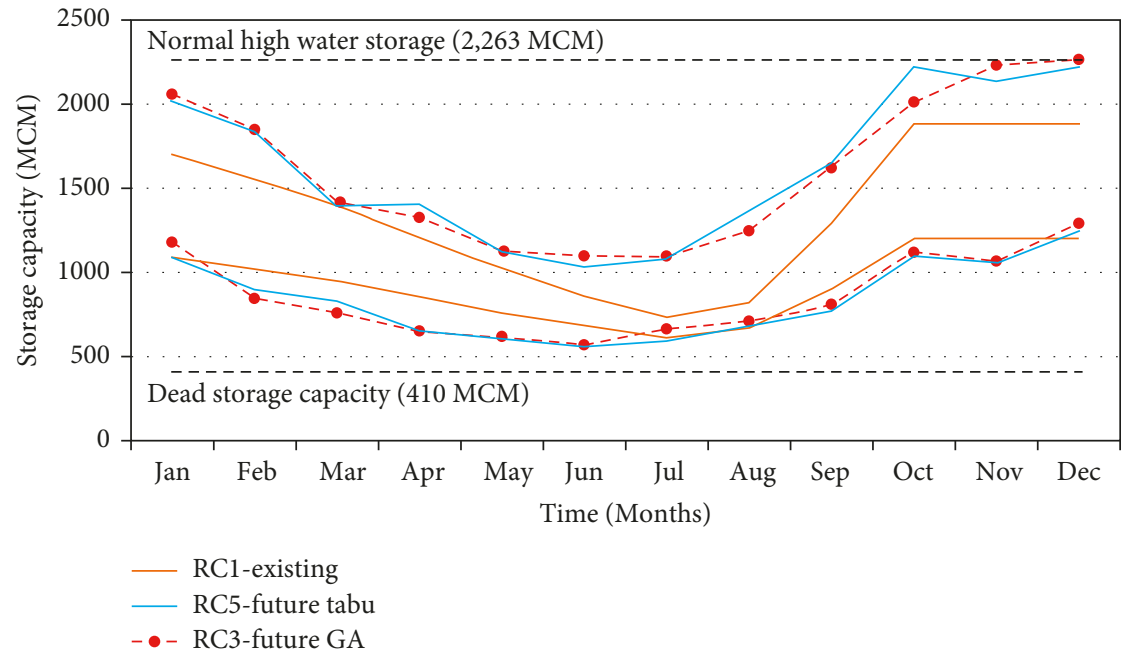

Figure 11: Optimal future rule curves of the Ubolrat Reservoir.

existing rule curves and the new rule curves obtained from the CTSA and CGA are similar.

The obtained rule curves also indicated that the water storage levels of the CTSA and CGA lower rule curves are lower than the existing rule curves during the dry season (February-June) in order to release more water to reduce water scarcity. In the middle of rainy season (AugustOctober), the CTSA and CGA upper curves are higher than their existing rule curves in order to increase water storage for next dry season. This will help alleviate water shortages in the next year. These patterns of the obtained curves are similar to the pattern of the other reservoirs in Thailand on the other studies $[7,10]$ because of seasonal effect.

3.3. Optimal Future Rule Curves. To find the future rule curves, the average monthly inflow for the future period 2015-2064 under the B2 scenario [27] was imported into the
CGA and CTSA model, and then, the optimal future rule curves were obtained. Figure 7 shows the optimal upper and lower rule curves of the CGA (RC3) and CTSA (RC5) compared with the existing rule curves (RC1). The results show that the patterns from the existing rule curves and the new future rule curves obtained from the CGA and CTSA are similar. The storage capacity of the upper rule curves of the CGA (RC3) and CTSA (RC5) were higher than the existing upper rule curves to reduce the spill water and to keep the storage capacity full at the end of the rainy season. This will help prevent water shortages in the following year. Whereas, during the dry season (February to June), the storage capacities of the RC3 and RC5 were lower than the existing rule curves in order to release more water for alleviating the problem of water shortages. These rule curve patterns are similar to those from previous studies on reservoir rule curves in Thailand, which were affected by the seasons $[7,10]$. 
TABLE 4: Situations of water shortage and excess release of the systems using historic inflow.

\begin{tabular}{|c|c|c|c|c|c|c|}
\hline \multirow{2}{*}{ Situations } & \multirow{2}{*}{ Rule curves } & \multirow{2}{*}{ Frequency (times/year) } & \multicolumn{2}{|c|}{ Magnitude (MCM/year) } & \multicolumn{2}{|c|}{ Duration (year) } \\
\hline & & & Average & Maximum & Average & Maximum \\
\hline \multirow{3}{*}{ Water shortage } & RC1 (existing) & 0.857 & 554.918 & 1,594 & 6.000 & 22.000 \\
\hline & RC2 (CGA) & 0.878 & 402.633 & 1,352 & 8.600 & 25.000 \\
\hline & RC4 (CTSA) & 0.959 & 455.776 & 1,324 & 15.667 & 34.000 \\
\hline \multirow{3}{*}{ Excess release } & RC1 (existing) & 0.612 & 578.319 & $3,323.422$ & 3.000 & 7.000 \\
\hline & RC2 (CGA) & 0.408 & 423.555 & $2,891.616$ & 2.857 & 5.000 \\
\hline & RC4 (CTSA) & 0.469 & 478.789 & $3,000.471$ & 2.556 & 6.000 \\
\hline
\end{tabular}

TABLE 5: Situations of water shortage of the systems using synthetic inflow from historic data.

\begin{tabular}{llccccc}
\hline \multirow{2}{*}{ Rule curves } & & Frequency (times/year) & \multicolumn{2}{c}{ Magnitude (MCM/year) } & \multicolumn{2}{c}{ Duration (year) } \\
& & & Average & Maximum & Average & Maximum \\
\hline \multirow{2}{*}{ RC1 (existing) } & $\mu$ & 0.889 & 532.169 & $1,482.370$ & 9.573 & 19.780 \\
& $\sigma$ & 0.037 & 25.134 & 144.076 & 3.414 & 6.538 \\
\hline \multirow{2}{*}{ RC2 (CGA) } & $\mu$ & 0.883 & 381.586 & $1,465.750$ & 9.248 & 20.190 \\
& $\sigma$ & 0.039 & 29.268 & 180.698 & 3.424 & 7.595 \\
\hline \multirow{2}{*}{ RC3 (CGA) } & $\mu$ & 0.918 & 427.853 & $1,431.100$ & 12.542 & 24.320 \\
& $\sigma$ & 0.032 & 27.612 & 188.318 & 5.252 & 8.507 \\
\hline \multirow{2}{*}{ RC4 (CTSA) } & $\mu$ & 0.728 & 391.612 & $1,453.790$ & 4.776 & 11.000 \\
& $\sigma$ & 0.051 & 28.749 & 177.480 & 1.348 & 4.306 \\
\hline \multirow{2}{*}{ RC5 (CTSA) } & $\mu$ & 0.911 & 404.437 & $1,442.930$ & 11.918 & \\
& $\sigma$ & 0.034 & 28.146 & 179.992 & 5.266 \\
\hline
\end{tabular}

Note: $\mu=$ average, $\sigma=$ standard deviation.

TABLE 6: Situations of excess water release of the systems using synthetic inflow from historic data.

\begin{tabular}{|c|c|c|c|c|c|c|}
\hline \multirow{2}{*}{ Rule curves } & & \multirow{2}{*}{ Frequency (times/year) } & \multicolumn{2}{|c|}{ Magnitude (MCM/year) } & \multicolumn{2}{|c|}{ Duration (year) } \\
\hline & & & Average & Maximum & Average & Maximum \\
\hline \multirow{2}{*}{ RC1 (existing) } & $\mu$ & 0.648 & 550.036 & $3,511.112$ & 2.817 & 7.140 \\
\hline & $\sigma$ & 0.045 & 33.939 & 825.296 & 0.534 & 1.939 \\
\hline \multirow{2}{*}{ RC2 (CGA) } & $\mu$ & 0.472 & 390.421 & $3,247.282$ & 2.304 & 5.590 \\
\hline & $\sigma$ & 0.051 & 39.386 & 808.863 & 0.461 & 1.843 \\
\hline \multirow{2}{*}{ RC3 (CGA) } & $\mu$ & 0.495 & 438.704 & $3,310.449$ & 2.163 & 5.330 \\
\hline & $\sigma$ & 0.050 & 36.914 & 785.299 & 0.410 & 1.596 \\
\hline \multirow{2}{*}{ RC4 (CTSA) } & $\mu$ & 0.482 & 400.120 & $3,197.957$ & 2.296 & 5.380 \\
\hline & $\sigma$ & 0.050 & 38.579 & 814.755 & 0.475 & 1.600 \\
\hline \multirow{2}{*}{ RC5 (CTSA) } & $\mu$ & 0.504 & 412.739 & $3,225.344$ & 2.457 & 5.850 \\
\hline & $\sigma$ & 0.051 & 37.803 & 801.793 & 0.525 & 1.866 \\
\hline
\end{tabular}

Note: $\mu=$ average, $\sigma=$ standard deviation.

TABLE 7: Situations of water shortage and excess release of the systems using future inflow.

\begin{tabular}{lcccccc}
\hline \multirow{2}{*}{ Situations } & \multirow{2}{*}{ Rule curves } & \multirow{2}{*}{ Frequency (times/year) } & \multicolumn{2}{c}{ Magnitude (MCM/year) } & \multicolumn{2}{c}{ Duration (year) } \\
& & & Average & Maximum & Average & Maximum \\
\hline \multirow{5}{*}{ Water shortage } & RC1 (existing) & 0.140 & 23.200 & 660.000 & 1.167 & 2.000 \\
& RC2 (CGA) & 0.240 & 9.340 & 412.000 & 1.200 & 2.000 \\
& RC4 (CTSA) & 0.340 & 32.860 & 418.000 & 1.417 & 4.000 \\
& RC3 (CGA) & 0.020 & 5.800 & 290.000 & 1.000 & 1.000 \\
& RC5 (CTSA) & 0.340 & 32.860 & 418.000 & 1.417 & 4.000 \\
\hline \multirow{5}{*}{ Excess release } & RC1 (existing) & 0.980 & $2,085.463$ & $4,711.864$ & 24.500 & 27.000 \\
& RC2 (CGA) & 0.980 & $2,056.182$ & $4,697.881$ & 24.500 & 27.000 \\
& RC4 (CTSA) & 0.980 & $2,085.965$ & $4,702.331$ & 24.500 & 27.000 \\
& RC3 (CGA) & 0.980 & $2,045.096$ & $4,689.417$ & 24.500 & 27.000 \\
& RC5 (CTSA) & 0.980 & $2,085.965$ & $4,702.331$ & 24.500 & 27.000 \\
\hline
\end{tabular}


3.4. Performance of Optimal Rule Curves. The evaluation of the new historic rule curves and future rule curves generated from the CGA and CTSA model aimed to determine the performance of the rule curves with the synthetic historic inflow of 500 samples and the future inflows (B2 scenario), as shown in Tables 4-7. Table 4 shows the situations of water shortage and excess release of the systems when considering historic inflow. It indicated that the magnitudes of water shortage and excess release of the systems using CGA and CTSA rule curves are less than the magnitudes of using existing rule curves (402.633 and 455.776 million cubic meters (MCM)/year for average water shortage of CGA and CTSA, resp.). Whereas the frequency and duration time of water shortage and excess release of the systems using CGA and CTSA rule curves are higher than the frequency and duration of using existing rule curves.

Tables 5 and 6 show the efficiency of the five rule curves for water shortage and excess release situations by considering the synthetic historic inflow of 500 samples. It indicates that the situations of water shortage and excess release when using the historic rule curves (RC2 and RC3) are less than using the existing rule curves ( $\mathrm{RC} 1)$ and the future rule curves (RC4 and RC5).

In the case of future situation (Table 7), the future rule curves (RC4 and RC5) showed the best performance, as indicated by the frequency of the water shortage and the average and the maximum magnitudes of the water shortages. The future rule curves are more suitable for future situations than the existing rule curves and the historic rule curve. It can be concluded that rule curves created using the specific inflow periods will be the most suitable. The proposed CTSA model is another search optimal technique, so the results are near optimality that closed to the results of the other search techniques based on the same condition. However, the efficiency of each technique was carried out on many studies $[7,10]$.

\section{Conclusion}

This study proposed an alternative algorithm for searching optimal reservoir rule curves. The conditional tabu search algorithm (CTSA) and reservoir simulation model were applied to search the optimal rule curves of the Ubolrat Reservoir under historic monthly inflow and future inflow under the scenario B2. The future inflow and synthetic inflow data of reservoirs were used to simulate reservoir system for evaluating situations of water shortage and excess release. The results found that the new obtained rule curves from CTSA are more suitable for reservoir operating than the existing rule curves. The frequency and magnitude of water shortage and excess water release for using new obtained rule curves are lower than the existing rule curves. When comparing the new obtained rule curves from CTSA with the rule curves of the CGA method as well as the existing simulation method, it was found that these rule curves are similar. The proposed CTSA model is an effective method for application to find optimal reservoir rule curves. This reveals that the CTSA and GA model with future inflow are effective methods for searching optimal reservoir rule curves that are suitable for using in the future situations.

\section{Conflicts of Interest}

The authors declare that there are no conflicts of interest regarding the publication of this paper.

\section{Acknowledgments}

This research was financially supported by Mahasarakham University and National Research Council of Thailand Grant Year 2018.

\section{References}

[1] X. Li, S. Gao, P. Liu, and G. Chen, "Dynamic control of flood limited water level for reservoir operation by considering inflow uncertainty," Journal of Hydrology, vol. 391, no. 1-2, pp. 124-132, 2010.

[2] P. Liu, L. Li, G. Chen, and D. E. Rheinheimer, "Parameter uncertainty analysis of reservoir operating rules based on implicit stochastic optimization," Journal of Hydrology, vol. 514, pp. 102-113, 2014.

[3] T. Zhao, X. Cai, and D. Yang, "Effect of streamflow forecast uncertainty on real-time reservoir operation," Advances in Water Resources, vol. 34, no. 4, pp. 495-504, 2011.

[4] E. Fallah-Mehdipour, O. B. Haddad, and M. A. Mariño, "Realtime operation of reservoir system by genetic programming," Water Resources Management, vol. 26, no. 14, pp. 4091-4103, 2012.

[5] S. K. Jain, M. K. Goel, and P. K. Agarwal, "Reservoir operation study of Sabarmati system, India," Journal of Water Resources Planning and Management, vol. 124, no. 1, pp. 31-38, 1998.

[6] Electricity Generating Authority of Thailand (EGAT), "Manual for operating the Bhumibol and Sirikit Reservoirs," EGAT Research Report, Bangkok, Thailand, 2004.

[7] C. Chaleeraktrakoon and A. Kangrang, "Dynamic programming with the principle of progressive optimality for searching rule curves," Canadian Journal of Civil Engineering, vol. 34, no. 2, pp. 170-176, 2007.

[8] F. J. Chang, L. Chen, and L. C. Chang, "Optimizing the reservoir operating rule curves by genetic algorithms," Hydrological Processes, vol. 19, no. 11, pp. 2277-2289, 2005.

[9] C. H. Yeh, "Applying multi-objective genetic algorithms for planning of flood detention dams system," Taiwan Water Conservancy, vol. 45, no. 2, pp. 70-81, 1997.

[10] A. Kangrang, S. Compliew, and R. Hormwichian, "Optimal reservoir rule curves using simulated annealing," Proceedings of the Institution of Civil Engineers-Water Management, vol. 164, no. 1, pp. 27-34, 2011.

[11] T. Zhang, "A hybrid particle swarm optimization and tabu search algorithm for order planning problems of steel factories based on the make-to-stock and make-to-order management architecture," Journal of Industrial and Management Optimization, vol. 7, no. 1, pp. 31-51, 2011.

[12] M. D. C. Cunha and L. Ribeiro, "Tabu search algorithms for water network optimization," European Journal of Operational Research, vol. 157, no. 3, pp. 746-758, 2004.

[13] F. Glover and M. Laguna, Tabu Search, Kluwer Academic Publishers, Dordrecht, Netherlands, 1997.

[14] U. Faigle and W. Kern, "Some convergence results for probabilistic tabu search," ORSA Journal on Computing, vol. 4, no. 1, pp. 32-37, 1992.

[15] W. Sa-ngiamvibool, S. Pothiya, and I. Ngamroo, "Multiple tabu search algorithm for economic dispatch problem 
considering valve-point effects," Electrical Power and Energy Systems, vol. 33, no. 4, pp. 846-854, 2011.

[16] G. Lacombe, C. T. Hoanh, and V. Smakhtin, "Multi-year variability or unidirectional trends? mapping long-term precipitation and temperature changes in continental Southeast Asia using PRECIS regional climate model," Climatic Change, vol. 113, no. 2, pp. 285-299, 2012.

[17] Southeast Asia START Regional Center, "Preparation of climate change scenarios for climate change impact assessment in Thailand," Final Report, Bangkok, Thailand, 2010.

[18] A. G. Arnold, R. Srinivasan, R. S. Muttiah, and J. R. Williams, "Large area hydrologic modeling and assessment pert I: model development," Journal of American Water Resource Association, vol. 34, no. 1, pp. 73-89, 1998.

[19] M. T. Vu, V. S. Raghavan, and S. Y. Liong, "Ensemble climate projection for hydro-meteorological drought over the river basin in central highland, Vietnam," KSCE Journal of Civil Engineering, vol. 19, no. 2, pp. 427-433, 2015.

[20] M. Meaurio, A. Zabaleta, J. Yriarte, R. Srinivasan, and I. Antigürdad, "Evaluation of SWAT models performance to simulate streamflow spatial origin. The case of a small forested watershed," Journal of Hydrology, vol. 525, pp. 326-334, 2015.

[21] A. Rittama, "Hedging policy for reservoir system operation: a case study of Mun Bon and Lam Chae Reservoirs," Kasetsart Journal, vol. 43, pp. 833-842, 2009.

[22] T. R. Neelakanta and K. Sasireka, "Hydropower reservoir operation using standard operating and standard hedging policies," International Journal of Engineering and Technology, vol. 5, no. 2, pp. 1191-1196, 2013.

[23] A. Tayebiyan, T. A. M. Ali, A. H. Ghazali, and M. A. Malek, "Optimization of exclusive release policies for hydropower reservoir operation by using genetic algorithm," Water Resources Management, vol. 30, no. 3, pp. 1203-1216, 2016.

[24] IPCC, Summary of Policymakers: Emission Scenarios: A Special Report of IPCC Workgroup III of the Intergovernmental Panel on Climate Change, IPCC, Geneva, Switzerland, 2000.

[25] W. Buakhao and A. Kangrang, "DEM resolution impact on the estimation of the physical characteristics of watersheds by using SWAT," Advances in Civil Engineering, vol. 2016, Article ID 8180158, 9 pages, 2016.

[26] A. W. Alansi, M. S. M. Amin, G. Abdul Halim, H. Z. M. Shafri, and W. Aimrun, "Validation of SWAT model for stream flow simulation and forecasting in Upper Bernam humid tropical river basin, Malaysia," Hydrology and Earth System Sciences Discussions, vol. 6, no. 6, pp. 7581-7609, 2009.

[27] A. Kangrang, H. Prasanchum, and R. Hormwichian, "Future runoff under land use and climate changes in the Ubolratana Basin, Thailand," International Journal of Ecology \& Development, vol. 32, no. 3, pp. 53-66, 2017.

[28] C. Chiamsathit, A. J. Adeloye, and B. S. Soundharajan, "Assessing competing policies at Ubonratana reservoir, Thailand," Proceeding of the Institution of Civil Engineering-Water Management, vol. 167, no. 10, pp. 551-560, 2015. 


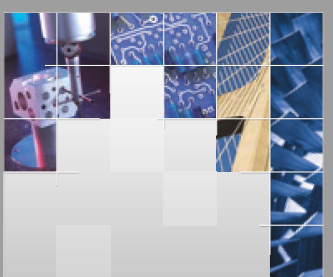

\section{Enfincering}
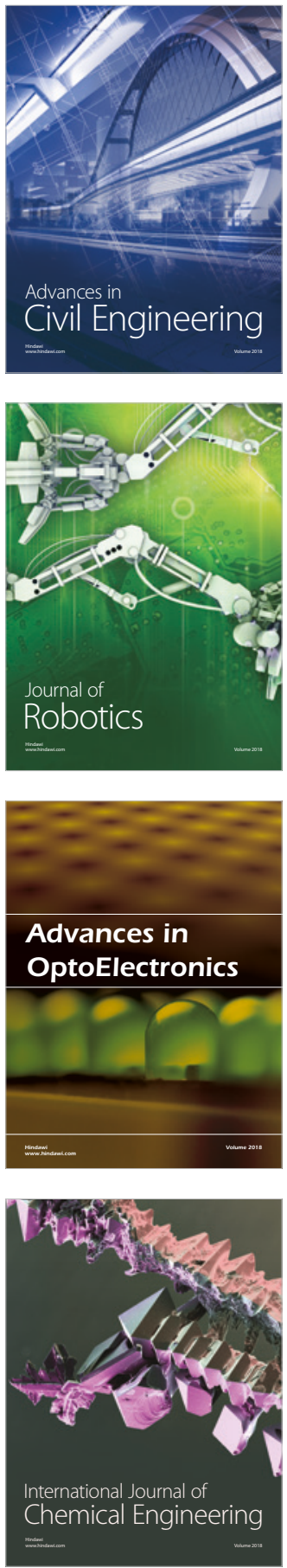

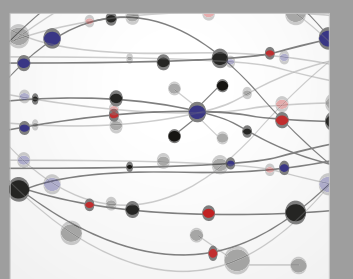

\section{Rotating \\ Machinery}

The Scientific World Journal

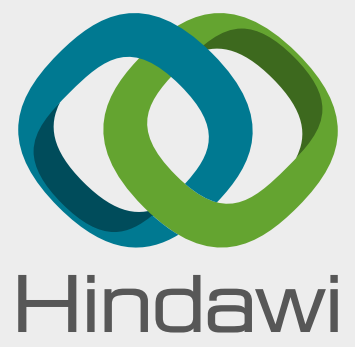

Submit your manuscripts at

www.hindawi.com
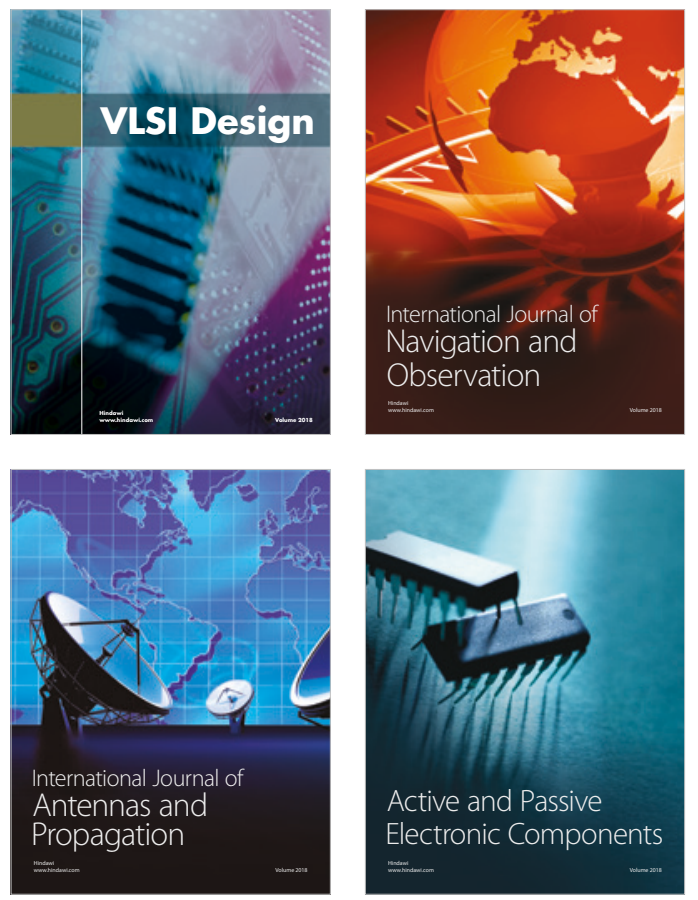
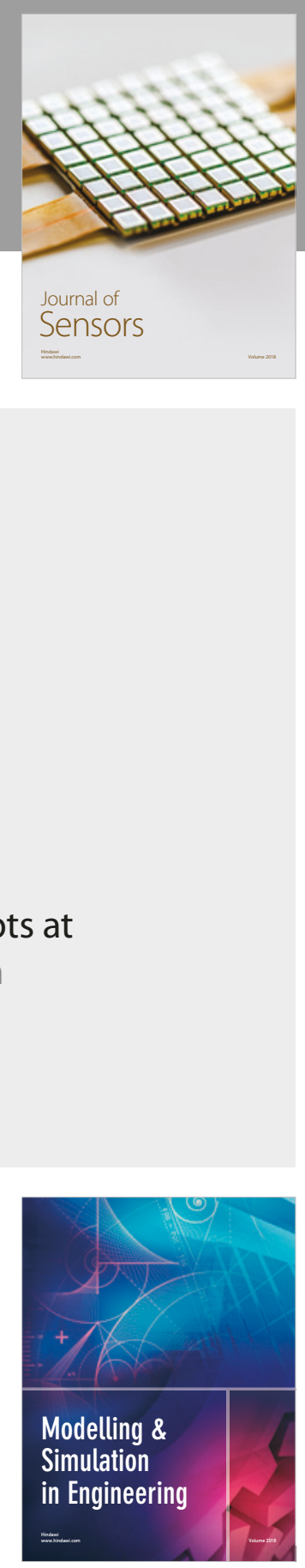

\section{Advances \\ Multimedia}
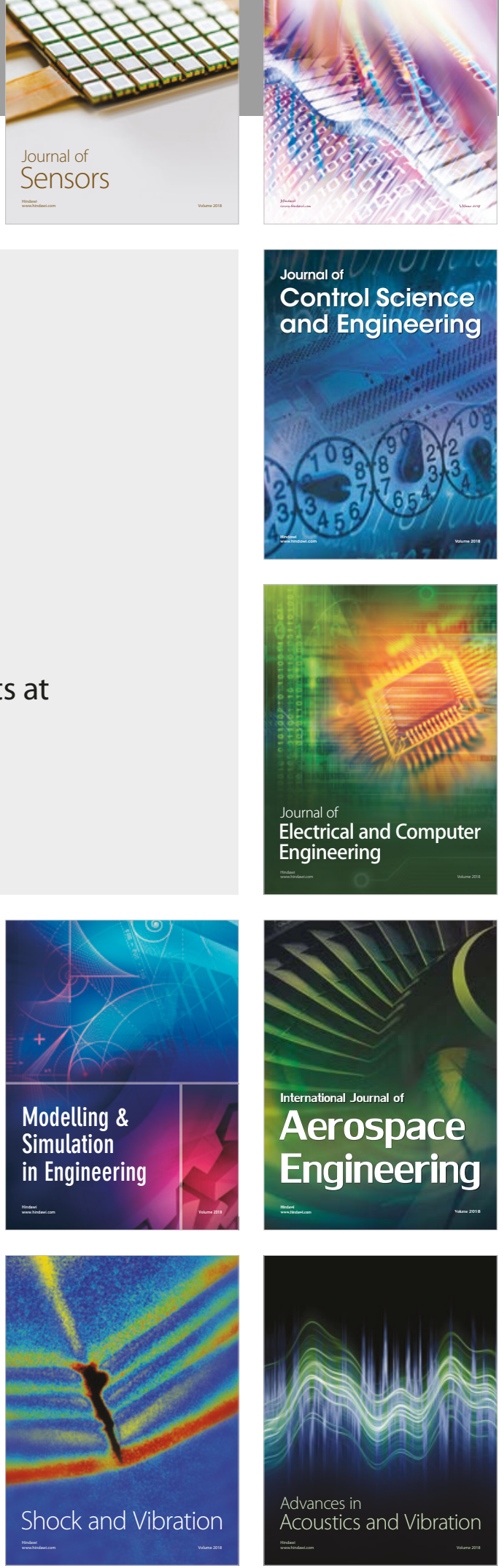